\title{
The 4G/4G Plasminogen Activator Inhibitor-1 Genotype Is Associated With Frequent Recurrence of Acute Otitis Media
}

\author{
Marieke Emonts, MDa, Selma P. Wiertsema, PhD ${ }^{b}$, Reinier H. Veenhoven, MD, PhDc, Jeanine J. Houwing-Duistermaat, PhDd, \\ Vanessa Walraven, BA ${ }^{b}$, Ronald de Groot, MD, PhDe, Peter W. M. Hermans, PhDe, Elisabeth A. M. Sanders, MD, PhD
}

aDepartment of Pediatrics, Erasmus MC-Sophia Children's Hospital, University Medical Center, Rotterdam, Netherlands; bDepartment of Pediatric Immunology, University Medical Centre, Utrecht, Netherlands; ' Department of Pediatrics, Spaarne Hospital, Hoofddorp, Netherlands; 'Department of Medical Statistics, Leiden University Medical Centre, Leiden, Netherlands; 'Department of Pediatrics, Radboud University Nijmegen Medical Centre, Nijmegen, Netherlands

The authors have indicated they have no financial relationships relevant to this article to disclose.

\section{ABSTRACT}

OBJECTIVES. Plasminogen activator inhibitor-1 counterregulates cell migration, adhesion, and tissue repair. The PAII 4G/5G promoter polymorphism has an effect on expression levels of PAII. After a first acute otitis media episode, children are at increased risk for a next episode. Because the PAIl $4 \mathrm{G}$ allele is associated with higher plasminogen activator inhibitor-1 production and, hence, decreased tissue repair, we hypothesize that this allele may contribute to increased recurrence of acute otitis media.

PATIENTS AND METHODS. The PAII 4G/5G polymorphism was genotyped in 348 Dutch children aged 1 to 7 years who were suffering from recurrent acute otitis media and participating in a randomized, controlled trial and 463 healthy control subjects, representative of the general population.

RESULTS. No significant difference in PAIl genotype distribution between the whole acute otitis media group and control subjects was observed. However, children with the PAII 4G/4G genotype had an increased risk of more frequent acute otitis media episodes compared with those who were homozygous for the $5 \mathrm{G}$ variant, also after correction for cofactors. This finding was attributable to children $<4$ years of age.

CONCLUSIONS. Our findings suggest that the PAII 4G/4G genotype is associated with an increased risk for the otitis-prone condition, potentially because of impaired healing after a previous otitis media episode. 
$\mathrm{A}$ CUTE OTITIS MEDIA (AOM) is the most common infection in children, but the number of AOM episodes varies markedly between patients. Approximately $10 \%$ to $15 \%$ of all children suffer from $\geq 4$ episodes per year and are considered otitis prone. ${ }^{1-3}$ One of the most prominent risk factors seems to be a first episode of AOM early in life predisposing to a next event. ${ }^{4,5}$ Other issues affecting the risk of developing recurrent middle ear infections include host factors like gender, age, atopy, and ethnic background. ${ }^{6}$ Environmental factors associated with recurrent AOM episodes are microbial exposure, like in day care or from older siblings, or triggers, like lack of breastfeeding or exposure to tobacco smoke. Often there is a family history of otitis media. 4,6,7 Twin studies have shown a heritability of $57 \%$ for acute ear infections and $72 \%$ for chronic ear infections. ${ }^{8-12}$ Furthermore, the correlation for recurrent otitis media is twofold higher in monozygotic twins (65\%-71\%) compared with dizygotic twins $(25 \%-34 \%) .{ }^{13}$ Genetic factors involved in inflammation and tissue repair may play a role in the development of recurrent AOM episodes and the otitis-prone condition. Delayed downregulation of the inflammatory response to infections in the middle ear cavity may play a role in priming the individual for additional AOM episodes. Plasminogen activator inhibitor-1 (PAI-1) is known to have an important role in fibrinolysis. ${ }^{14,15}$ In addition, PAI- 1 is involved in the inflammatory reaction, inhibits cell adhesion and migration, and delays tissue repair. ${ }^{16,17}$ The $4 \mathrm{G} / 5 \mathrm{G}$ insertiondeletion polymorphism at position -675 of the PAII gene is known to influence the expression of PAI-1. ${ }^{18,19}$ Individuals homozygous for the $4 \mathrm{G}$ allele have higher PAI-1 concentrations in peripheral blood than those with the $4 \mathrm{G} / 5 \mathrm{G}$ or $5 \mathrm{G} / 5 \mathrm{G}$ genotypes. ${ }^{20,21}$ The PAIl $4 \mathrm{G}$ allele has been reported previously to be associated with asthma, as well as with increased morbidity and mortality in meningococcal disease. ${ }^{20,22-25}$

We hypothesized that the PAIl 4G/4G genotype, known to result in high PAI- 1 concentrations, which is associated with decreased tissue integrity, is associated with recurrence of otitis media. In this study, we investigated the association between this PAIl polymorphism and recurrent AOM. Our results show that $4 \mathrm{G}$ homozygous individuals have an increased risk for an otitisprone condition, especially under the age of 4 years.

\section{METHODS}

\section{Participants}

Patients who initially participated in a randomized, controlled study on prevention of recurrent AOM by pneumococcal vaccinations were included in this study. ${ }^{26}$ Parents were informed about the study by primary care physicians, pediatricians, and otolaryngologists from across the Netherlands. Children were enrolled in the study after obtaining approval of the medical ethical committee of the Utrecht University Medical Centre and informed consent from the parents or guardians. DNA was available from 348 Dutch white children, 1 to 7 years of age, who were suffering from recurrent AOM defined as $\geq 2$ AOM episodes in the preceding year. The number of AOM episodes before vaccination was based both on parental report (AOM defined as having $\geq 1$ of the symptoms: acute earache, new-onset otorrhea, irritability, and fever) and on clinical information of the diagnosis by a physician. In the present study cohort, 122 children suffered from 2 to 3 otitis media episodes in the year preceding inclusion, whereas 226 suffered from $\geq 4$ episodes (otitis-prone condition). ${ }^{3}$ No children with $<2$ AOM episodes were included in the vaccination trial. In addition, children with primary or secondary immunodeficiency, cystic fibrosis, immotile cilia syndrome, chromosomal abnormalities such as Down syndrome, and craniofacial abnormalities such as cleft palate were excluded from the study. The history of atopy, defined as eczema, hay fever, recurrent wheezing, or asthma, and the number of AOM episodes in the year before inclusion were assessed by the questionnaire filled out by all of the patients and their parents at inclusion in the study. Otorrhea duration was assessed in 214 children for whom PAIl genotypes were available. Patient characteristics are described in Table 1. Healthy adult Dutch white control subjects $(n=463)$ were derived from the Dutch Blood Bank Sanquin. No records of previous history regarding AOM were available for these control subjects; however, in the general population, a total number of $\leq 3.2$ AOM episodes is expected in childhood. ${ }^{3}$ This implies that control subjects will have had, on average, much fewer AOM episodes per year than the patients. Blood was sampled for DNA isolation. DNA isolation from donor buffy coats was performed according to standard protocols using a QIAamp DNA mini kit (Qiagen, Valencia, CA).

\section{Experimental Procedures}

PAI1 - 675 genotype (rs 1799889) was determined using single base extension analysis, a technique commonly used in our laboratory (ABI Prism, SNaPshot Multiplex kit; Applied Biosystems, Foster City, CA). The genomic region of interest was amplified using polymerase chain reaction (37 cycles; annealing temperature of $60^{\circ} \mathrm{C}$; total volume of $10 \mu \mathrm{L}$ ) with the following primers: forward, 5'-CAGCCAGACAAGGTTGTT-3', and reverse 5' -CCACCCGGTGCTCT-3'. Amplification resulted in a 265-nucleotide polymerase chain reaction product. After purification with Shrimp Alkaline Phosphatase and Exonuclease I (both from Amersham Biosciences, Uppsala, Sweden), a single base extension with fluorescently labeled dideoxynucleotide triphosphates was performed using the reverse primer 5'-TTTTTGATACACGGCTGACTCCCC-3'. The poly-T tail allows us to distinguish primers in a multiplex analysis for which this assay was 


\begin{tabular}{|c|c|c|c|}
\hline Characteristics & $\begin{array}{c}2-3 \text { AOM Episodes } \\
(N=122)\end{array}$ & $\begin{array}{l}\geq 4 \text { AOM Episodes } \\
\quad(N=226)\end{array}$ & pa \\
\hline Male gender, $n(\%)$ & $84(69)$ & $128(57)$ & .03 \\
\hline Age, median (range), y & $2.42(1.0-6.3)$ & $2.10(1.0-7.0)$ & .40 \\
\hline Age group (12-48 mo), $n$ (\%) & $84(69)$ & $180(80)$ & .03 \\
\hline Age at first $\mathrm{AOM}$, geometric mean (SD), mo & $10.1(2.0)$ & $7.7(2.1)$ & .001 \\
\hline Breastfeeding $\geq 3 \mathrm{mo}, n(\%)$ & $57(47)$ & $96(43)$ & .50 \\
\hline Tobacco smoke exposure indoors, $n(\%)$ & $41(34)$ & $70(31)$ & .63 \\
\hline \multicolumn{4}{|l|}{ Day care } \\
\hline At age $12-24$ mo, n/N (\%) & $22 / 44(50)$ & 42/99 (42) & .47 \\
\hline At age $25-48$ mo, n/N (\%) & 70/78 (90) & 113/127 (89) & 1.00 \\
\hline No. of siblings, median (range); mean & $1.0(0-3) ; 0.93$ & $1.0(0-7) ; 1.17$ & .02 \\
\hline \multicolumn{4}{|l|}{ Family history positive for AOM } \\
\hline Parents (121/225), n (\%) & $79(65)$ & $131(58)$ & .21 \\
\hline Siblings, $n / N(\%)$ & 48/86 (56) & 98/182 (54) & .79 \\
\hline Atopy, $n(\%)^{\mathrm{b}}$ & $54(44)$ & $117(52)$ & .22 \\
\hline
\end{tabular}

originally designed. The products generated were analyzed on an ABI Prism 3100 genetic analyzer using GeneScan Analysis Software (Applied Biosystems). When no clear genotype was obtained or no consensus was reached between 2 independent investigators, genotypes were excluded from the analyses.

\section{Statistical Analyses}

Statistical analyses were performed by using SPSS 11.0 (SPSS Inc, Chicago, IL). A comparison of genotype frequencies was made between patients and blood donor control subjects assuming a multiplicative model. ${ }^{27} \mathrm{Bi}$ nomial variables were analyzed using Pearson's $\chi^{2}$ test or Fisher's exact test when appropriate. Continuous variables were compared for the different genotypes using the Mann-Whitney $U$ test (nonparametric) or $t$ test (normal distribution). Within the patient sample, only genotype distributions of children suffering from 2 to 3 episodes per year before vaccination were compared with those of individuals who had $\geq 4$ episodes after correction for age at study entry, gender, number of siblings, and the log-transformed age at the time of the first episode of AOM, using binary logistic regression. The log-transformed age at the time of the first AOM episode was included in the analysis, because age at the first AOM episode itself did not show a normal distribution and an early first infection predisposes to a second AOM episode. A child who has had a first AOM episode at a younger age has had a longer period of time to develop multiple AOM episodes than a child of the same age who suffered from the first infection at a later age. Because the interaction between the age at the first AOM episode and the age of inclusion was significant, this was accounted for in the analyses. Because the pathogenesis of AOM in young children may differ from older children because of an immature immune system and different anatomic features such as the Eustachian tube, we also analyzed separately the frequencies of the number of AOM episodes in the year before inclusion in patients 1 to 4 years of age and patients $>4$ years. Presence of atopy did not differ between the otitis-prone children and those with fewer episodes. Because asthma cannot, by definition, be diagnosed in children $<6$ years of age, which applies to the main fraction of our patient cohort, recurrent wheezing and asthma as reported by the parents were considered the same in the statistical analyses. In addition to the multiplicative model, the effect of PAII genotype on the number of AOM episodes was also assessed comparing 4G/4G homozygotes with those homozygous for the $5 \mathrm{G}$ allele.

\section{RESULTS}

\section{The PAl1 4G/4G Genotype Is Not Associated With Initial Susceptibility to AOM}

The PAIl -675 polymorphism was successfully genotyped in 463 control subjects and 317 children with recurrent AOM. PAIl genotype frequencies in the control population were in Hardy-Weinberg equilibrium, and the allele frequencies were similar to results published previously. ${ }^{24}$ The distribution of genotypes in control subjects was as follows: $5 \mathrm{G} / 5 \mathrm{G}, 99(21.4 \%) ; 4 \mathrm{G} / 5 \mathrm{G}$, 241 (52.1\%); and 4G/4G, 123 (26.6\%). A significant difference in genotype distribution was only found between control subjects and those patients suffering from $\geq 4$ episodes of AOM $(P=.02)$. No difference was observed between patients having 2 to 3 AOM episodes a year and control subjects $(P=.34$; Table 2$)$.

\section{Related Epidemiologic Findings}

In our patient population, log-transformed age at first $\mathrm{AOM}$, gender, and the number of siblings were related to AOM recurrence rates (Table 1). Children who suffered from $\geq 4$ episodes in the year before inclusion had their 
TABLE 2 Comparison of PAI1 4G/5G Genotype Distribution in Patients With Recurrent Otitis Media and Control Subjects

\begin{tabular}{|c|c|c|c|c|c|c|c|}
\hline \multirow[t]{2}{*}{ PAl1 4G/5G } & \multirow{2}{*}{$\begin{array}{l}\text { Control Subjects } \\
\qquad \begin{array}{c}(N=463) \\
n(\%)\end{array}\end{array}$} & \multirow{2}{*}{$\begin{array}{l}2-3 \text { Episodes of AOM } \\
\quad(N=115), n(\%)\end{array}$} & \multirow{2}{*}{$\begin{array}{l}\geq 4 \text { Episodes of AOM } \\
\quad(N=202), n(\%)\end{array}$} & \multicolumn{2}{|c|}{$4 \mathrm{G} / 4 \mathrm{G}$ vs $5 \mathrm{G} / 5 \mathrm{G}$} & \multirow{2}{*}{$\begin{array}{c}2-3 \text { vs } \geq 4 \\
\text { Crude OR }(P)^{d}\end{array}$} & \multirow{2}{*}{$\begin{array}{c}2-3 \text { vs } \geq 4 \\
\text { Adjusted } \mathrm{OR}(P)^{\mathrm{c}, \mathrm{d}}\end{array}$} \\
\hline & & & & $\begin{array}{l}\text { Control vs } \\
2-3, \text { OR }(P)^{\mathrm{a}}\end{array}$ & $\begin{array}{l}\text { Control vs } \\
\geq 4, \text { OR }(P)^{\mathrm{b}}\end{array}$ & & \\
\hline \multicolumn{6}{|l|}{ All patients } & $1.59(.01)$ & $1.52(.03)$ \\
\hline $5 G / 5 G$ & $99(21.4)$ & $26(22.6)$ & $28(13.9)$ & $1.00^{e}$ & $1.00^{e}$ & $1.0 e^{e}$ & $1.00^{e}$ \\
\hline $4 \mathrm{G} / 5 \mathrm{G}$ & $241(52.1)$ & $65(55.6)$ & $109(54.0)$ & $1.03(.92)$ & $1.60(.05)$ & $1.56(.16)$ & $1.57(.18)$ \\
\hline $4 \mathrm{G} / 4 \mathrm{G}$ & $123(26.6)$ & $24(20.9)$ & 65 (32.2) & $0.74(.34)$ & $1.87(.02)$ & $2.52(.01)^{f}$ & $2.31(.03)^{f}$ \\
\hline \multicolumn{6}{|l|}{ Patients $<4 y$} & $1.75(.01)^{d}$ & $1.72(.02)^{\mathrm{d}}$ \\
\hline $5 G / 5 G$ & & $18(23.4)$ & $25(15.8)$ & & & $1.00^{e}$ & $1.00^{e}$ \\
\hline $4 G / 5 G$ & & $48(62.3)$ & $85(53.8)$ & & & $1.28(.50)$ & $1.32(.47)$ \\
\hline $4 \mathrm{G} / 4 \mathrm{G}$ & & $11(14.3)$ & $48(30.4)$ & & & $3.14(.01)^{f}$ & $2.97(.02)^{f}$ \\
\hline \multicolumn{6}{|l|}{ Patients $\geq 4 y$} & $1.53(.21)^{d}$ & $1.17(.69)^{\mathrm{d}}$ \\
\hline $5 G / 5 G$ & & $8(21.1)$ & $3(6.8)$ & & & $1.00^{\mathrm{e}}$ & $1.00^{\mathrm{e}}$ \\
\hline $4 \mathrm{G} / 5 \mathrm{G}$ & & $17(44.7)$ & $24(54.5)$ & & & $3.77(.08)$ & $5.25(.06)$ \\
\hline $4 \mathrm{G} / 4 \mathrm{G}$ & & $13(34.2)$ & $17(38.6)$ & & & $3.49(.11)^{f}$ & $2.50(.30)^{f}$ \\
\hline \multicolumn{8}{|c|}{$\begin{array}{l}\text { a Data are for patients with } 2 \text { to } 3 \text { episodes of AOM versus control subjects: } P=.45\left(\chi^{2}\right) \text {. } \\
\text { b Data are for patients with } \geq 4 \text { episodes of AOM versus control subjects: } P=.05\left(\chi^{2}\right) \text {. } \\
\text { c Adjusted ORs depicted were corrected for age at study entry, gender, number of siblings, and the log-transformed age at the time of the first episode of AOM. } \\
\text { d ORs represent the effect of the } P A / 14 G / 5 G \text { polymorphism (binary logistic regression analysis, multiplicative model). } \\
\text { e The reference OR is } 1.00 \text {. }\end{array}$} \\
\hline
\end{tabular}

first AOM episode at a significantly younger age compared with the children suffering from 2 to 3 episodes. Although the majority in the total group of children with AOM were boys, girls were overrepresented in the group of children suffering from $\geq 4$ AOM episodes when compared with the group of children with 2 to $3 \mathrm{AOM}$ episodes. The number of siblings was higher in the otitisprone group compared with the children with 2 to 3 episodes. Age at inclusion was not significantly different when comparing the group of children suffering from 2 to 3 AOM episodes with the group with $\geq 4$ episodes. However, when children were divided into groups under and over the age of 4 years, the distribution of AOM frequency differed significantly (Fig 1). The occurrence of atopy and the presence of a family history positive for AOM did not differ between children with 2 to 3 vs $\geq 4$ episodes of AOM.

\section{The PAI1 4G/4G Genotype Is Associated With the Otitis-Prone Condition in Children $<4$ Years of Age}

Comparing patients having 2 to $3 \mathrm{AOM}$ episodes to those with $\geq 4$, the log-odds ratio (OR) of the $4 \mathrm{G} / 4 \mathrm{G}$ versus $5 \mathrm{G} / 5 \mathrm{G}$ genotype was $\sim 2$ times the logOR of the $4 \mathrm{G} / 5 \mathrm{G}$ versus 5G/5G genotype (OR: 2.52; logOR: 0.4 and OR: 1.52; $\log$ OR: 0.19 , respectively; Table 2 ). Hence, the $4 \mathrm{G}$ allele probably has a multiplicative effect on AOM recurrence rate. ${ }^{27}$ After correction for confounding factors as described in "Statistical Analyses," we still found that the PAII 4G/4G genotype was associated with recurrence of disease in patients $(P=.01$, crude OR: 1.59; $P=$ .03 , adjusted OR: 1.52). The PAII 4G/4G individuals had an increased risk for $\geq 4 \mathrm{AOM}$ episodes compared with patients homozygous for the $5 \mathrm{G}$ variant $(P=.01$, crude OR: 2.52; $P=.03$, adjusted OR: 2.31). Because the

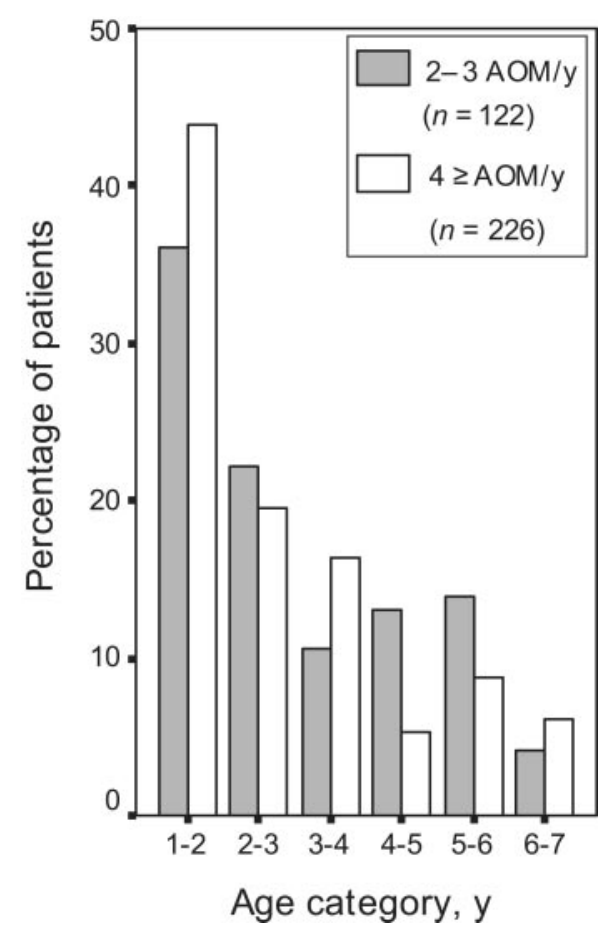

FIGURE 1

Distribution of the number of AOM episodes for different age categories at the time of inclusion. The number of patients (age category in years) for the group of children with 2 to 3 AOM episodes in the year before inclusion is $44(1-2), 27(2-3), 13(3-4), 16(4-5), 17$ $(5-6)$, and $5(6-7)$. The number of patients (age category) for the group of children with $\geq 4$ AOM episodes in the year before inclusion is $99(1-2), 44(2-3), 37(3-4), 12(4-5), 20$ $(5-6)$, and $14(6-7)$. The distribution of 2 to 3 vs $\geq 4$ AOM episodes differs between patients $<4$ and $>4$ years of age $(P=.03)$.

distribution of the number of AOM episodes differed between the groups of children 1 to 4 years of age and $>4$ years of age, these groups were also analyzed separately (Fig 1). The association of the PAIl 4G/4G geno- 
type with the otitis-prone condition was only found in the group of children 1 to 4 years of age $(P=.01$, crude OR: $1.75 ; P=.02$, adjusted OR: 1.72; Table 2). Comparing the children with PAII 4G/4G genotype with those homozygous for the $5 \mathrm{G}$ allele yielded a crude $\mathrm{OR}$ of 3.14 $(P=.01$; adjusted OR: $2.97, P=.02)$. The PAIl 4G/4G genotype was not significantly associated with the otitisprone condition in children $>4$ years of age. The number of days with otorrhea showed a trend toward longer duration in the $4 \mathrm{G}$ homozygous children (geometric mean days [SD] for genotypes: $5 \mathrm{G} / 5 \mathrm{G}, 5.3$ [3.9]; 4G/5G, 6.5 [4.0]; and 4G/4G, 7.2 [4.2]). This was, however, not significant $(P=.66$, analysis of variance).

\section{DISCUSSION}

In this study we show that, in the patient group with a history of $\geq 2$ AOM episodes, children 1 to 4 years of age, with the PAII 4G/4G genotype, which is related to high PAI-1 levels, have increased risk for more frequent recurrent AOM. ${ }^{18,19}$ The association is significant even after correction for possible confounding factors, with only a minimal change in ORs. PAI- 1 inhibits cellular migration and invasion, processes essential in tissue repair in inflammatory disease. ${ }^{16,17}$ Hence, higher PAI-1 levels might result in longer persistence of tissue inflammation or abnormally repaired tissue prone to bacterial colonization and new infections.

Two possible mechanisms for PAI-1 interaction and inhibition of tissue repair have been proposed. First, PAI-1 may inhibit a proteolytic cascade at the cell surface that results in matrix destruction, allowing cellular migration and invasion for tissue repair. The proteolytic cascade mechanism involves the activation of surfacebound plasminogen by surface-bound urokinase plasminogen activator (UPA). PAI- 1 can bind to uPA on the cell surface and inhibit its proteolytic activity and, hence, tissue repair. ${ }^{15,28,29}$ A second proposed pathway involves competitive binding of PAI- 1 and integrin to vitronectin. Both share the same binding site region on vitronectin. Vitronectin/integrin interaction is needed for cell migration and adhesion. The inhibiting effect of PAI- 1 is negated when excess nonsurface-bound uPA forms a complex with PAI-1 resulting in a release of PAI-1 from vitronectin, which is then available for interaction with integrin, favoring cell adhesion. ${ }^{30}$

A possible role for high PAI- 1 concentrations in the stronger inhibition of healing of inflamed otolaryngeal tissue that may, thus, favor an otitis-prone condition is supported by the results of Hansson et $\mathrm{al}^{31}$ that imply a further role for PAI-1 and plasminogen in tissue repair. They have shown that perforated tympanic membranes (TMs) of plasminogen-deficient mice exhibit reduced healing 15 days after myringectomy compared with TM from wild-type mice. Intravenous administration of plasminogen, in plasminogen-deficient mice, resulted in restored TM healing even if plasminogen was administered
30 days after perforation. The distribution of inflammatory cells in the perforated TM differed significantly between plasminogen-deficient and wild-type mice in vivo. Plasminogen-deficient mice with initially normal TMs showed spontaneous development of middle ear effusion. Interestingly, in an otherwise healthy 10-yearold boy with a history of chronic otitis media, low levels of serum plasminogen were detected. ${ }^{32}$ Interaction of PAI-1 with uPA prohibits catalytic activation of plasminogen to plasmin. High PAI-l levels might, therefore, result in similar clinical findings as seen in plasminogen deficiency.

Furthermore, in skin wound healing, PAI-1, uPA, and UPA receptor are expressed at the site of regenerative epithelial outgrowths at the edge of the wound. ${ }^{33,34}$ Plasminogen-deficient mice showed impaired wound healing. ${ }^{35}$ In addition, Chen et $\mathrm{al}^{36}$ reported that uPA expression is increased on infection with Streptococcus pneumoniae in an otitis media model in the rat. $S$ pneumoniae is one of the major causative microbes of otitis media in humans. ${ }^{37-39}$ We recognize that these findings do not prove a role for PAI- 1 in AOM, but we do feel that they deserve further attention. Additional functional assays in an otitis model are needed to further investigate the precise role of PAI-1 in AOM. These studies would preferably also be directed toward analyzing the therapeutic role of PAI-1 inhibitors and plasminogen in overcoming the effect of high PAI-1 expression and their effects on recurrence of otitis media.

We found that PAII 4G/4G had no effect on the initial susceptibility to AOM as reflected by the lack of significant differences between patients with AOM and control subjects. This fits in our concept of tissue repair where only once an episode of AOM has occurred may impaired tissue healing in $4 \mathrm{G}$ homozygous individuals facilitate microbial reinfection and the recurrence of otitis media. We realize that the control group was not an age-matched group without any AOM episodes, which may have biased our results. However, occurrence of AOM in the control subjects was $<2$ episodes per year based on the prevalence of AOM in childhood. The association between the PAII 4G/4G genotype and the otitis-prone condition remained significant even after correction of the effect of the polymorphism on AOM recurrence rates for gender, number of siblings, and both age and age at first AOM for the children $<4$ years of age. After 4 years of age we found a difference in the distribution of the number of AOM episodes compared with the younger children. AOM (and recurrence) has its peak in the first years of life. Ongoing recurrence in older children most likely selects a specific group that differs from the larger group of $10 \%$ to $15 \%$ of all children with recurrent AOM at early age. We possibly selected for the older patients as a result of the nature of the vaccination trial in which the patients included were 
more often otitis-prone children and particularly those at older age who had ongoing recurrent disease.

We only studied 1 genetic polymorphism in a complex multifactorial disease. As for many risk factors, only a small increase in risk can be found, which may be related to other risk factors as well. These may be both genetic and environmental. The balance of the different risk factors will determine the phenotype observed. Studying multiple factors simultaneously does, however, require large numbers of individuals. It must be mentioned that the association found in this study may reflect the result of linkage disequilibrium, meaning that not the PAII polymorphism itself but a genetic variation linked to this polymorphism is the actual disease-associated genetic variant. Additional studies are, therefore, required to confirm our findings. However, our data show that studies of genes involved in the inflammatory responses and tissue repair will be of significance in understanding recurrent AOM.

\section{CONCLUSIONS}

Individuals homozygous for the $4 \mathrm{G}$ allele show an increased risk for an otitis-prone condition, especially under the age of 4 years. Impaired tissue integrity, because of high PAI-1 levels in PAII 4G homozygous individuals once an episode of AOM has occurred, may possibly facilitate bacterial colonization and, thereby, the recurrence of otitis media.

\section{ACKNOWLEDGMENTS}

This work was supported by the Erasmus MC Revolving Fund Foundation (RF 2001/24).

The Sanquin Blood Bank South West Region provided samples of healthy blood donors. We thank Jon Laman, Department of Immunology, Erasmus MC, for critical reading of the article.

\section{REFERENCES}

1. Howie VM, Ploussard JH, Sloyer J. The "otitis-prone" condition. Am J Dis Child. 1975;129:676-678

2. Alho OP, Koivu M, Sorri M. What is an "otitis-prone" child? Int J Pediatr Otorhinolaryngol. 1991;21:201-209

3. Faden H, Duffy L, Boeve M. Otitis media: back to basics. Pediatr Infect Dis J. 1998;17:1105-1113

4. Harsten G, Prellner K, Heldrup J, Kalm O, Kornfalt R. Recurrent acute otitis media. A prospective study of children during the first three years of life. Acta Otolaryngol. 1989;107:111-119

5. Froom J, Culpepper L, Green LA, et al. A cross-national study of acute otitis media: risk factors, severity, and treatment at initial visit-report from the International Primary Care Network (IPCN) and the Ambulatory Sentinel Practice Network (ASPN). J Am Board Fam Pract. 2001;14:406-417

6. Rovers MM, Schilder AG, Zielhuis GA, Rosenfeld RM. Otitis media. Lancet. 2004;363:465-473

7. Rovers MM, Zielhuis GA, Ingels K, van der Wilt GJ. Day-care and otitis media in young children: a critical overview. Eur J Pediatr. 1999;158:1-6

8. Casselbrant ML, Mandel EM, Fall PA, et al. The heritability of otitis media: a twin and triplet study. JAMA. 1999;282: $2125-2130$

9. Casselbrant ML, Mandel EM. Genetic susceptibility to otitis media. Curr Opin Allergy Clin Immunol. 2005;5:1-4

10. Kvaerner KJ, Tambs K, Harris JR, Magnus P. Distribution and heritability of recurrent ear infections. Ann Otol Rhinol Laryngol. 1997; 106:624-632

11. Rovers M, Haggard M, Gannon M, Koeppen-Schomerus G, Plomin R. Heritability of symptom domains in otitis media: a longitudinal study of 1,373 twin pairs. Am J Epidemiol. 2002; 155:958-964

12. Casselbrant ML, Mandel EM, Rockette HE, et al. The genetic component of middle ear disease in the first 5 years of life. Arch Otolaryngol Head Neck Surg. 2004;130:273-278

13. Kvestad E, Kvaerner KJ, Roysamb E, Tambs K, Harris JR, Magnus P. Otitis media: genetic factors and sex differences. Twin Res. 2004;7:239-244

14. Kohler HP, Grant PJ. Plasminogen-activator inhibitor type 1 and coronary artery disease. $N$ Engl J Med. 2000;342:17921801

15. Irigoyen JP, Munoz-Canoves P, Montero L, Koziczak M, Nagamine $\mathrm{Y}$. The plasminogen activator system: biology and regulation. Cell Mol Life Sci. 1999;56:104-132

16. Kjoller L, Kanse SM, Kirkegaard T, et al. Plasminogen activator inhibitor-1 represses integrin- and vitronectin-mediated cell migration independently of its function as an inhibitor of plasminogen activation. Exp Cell Res. 1997;232:420-429

17. Stefansson S, Lawrence DA. The serpin PAI-1 inhibits cell migration by blocking integrin alpha $\mathrm{V}$ beta 3 binding to vitronectin. Nature. 1996;383:441-443

18. Dawson SJ, Wiman B, Hamsten A, Green F, Humphries S, Henney AM. The two allele sequences of a common polymorphism in the promoter of the plasminogen activator inhibitor-1 (PAI-1) gene respond differently to interleukin-1 in HepG2 cells. J Biol Chem. 1993;268:10739-10745

19. Eriksson P, Kallin B, van 't Hooft FM, Bavenholm P, Hamsten A. Allele-specific increase in basal transcription of the plasminogen-activator inhibitor 1 gene is associated with myocardial infarction. Proc Natl Acad Sci U S A. 1995;92:1851-1855

20. Hermans PW, Hibberd ML, Booy R, et al. 4G/5G promoter polymorphism in the plasminogen-activator-inhibitor-1 gene and outcome of meningococcal disease. Meningococcal Research Group. Lancet. 1999;354:556-560

21. Hoekstra T, Geleijnse JM, Schouten EG, Kluft C. Diurnal variation in PAI- 1 activity predominantly confined to the $4 \mathrm{G}$-allele of the PAI-1 gene. Thromb Haemost. 2002;88:794-798

22. Cho SH, Ryu CH, Oh CK. Plasminogen activator inhibitor-1 in the pathogenesis of asthma. Exp Biol Med (Maywood). 2004;229: $138-146$

23. Buckova D, Izakovicova Holla L, Vacha J. Polymorphism $4 \mathrm{G} / 5 \mathrm{G}$ in the plasminogen activator inhibitor-1 (PAI-1) gene is associated with IgE-mediated allergic diseases and asthma in the Czech population. Allergy. 2002;57:446-448

24. Haralambous E, Hibberd M, Ninis N, Hermans P, Nadel E, Levin $M$. The role of the functional plasminogen-activatorinhibitor-1 4G/5G promoter polymorphism in susceptibility, severity and outcome of meningococcal disease in Caucasian children. Crit Care Med. 2003;31:2788-2793

25. Geishofer G, Binder A, Muller M, et al. 4G/5G promoter polymorphism in the plasminogen-activator-inhibitor-1 gene in children with systemic meningococcaemia. Eur J Pediatr. 2005; $164: 486-490$

26. Veenhoven R, Bogaert D, Uiterwaal C, et al. Effect of conjugate pneumococcal vaccine followed by polysaccharide pneumococcal vaccine on recurrent acute otitis media: a randomised study. Lancet. 2003;361:2189-2195 
27. Sasieni PD. From genotypes to genes: doubling the sample size. Biometrics. 1997;53:1253-1261

28. Cubellis MV, Andreasen P, Ragno P, Mayer M, Dano K, Blasi F. Accessibility of receptor-bound urokinase to type-1 plasminogen activator inhibitor. Proc Natl Acad Sci US A. 1989;86: $4828-4832$

29. Stephens RW, Pollanen J, Tapiovaara H, et al. Activation of pro-urokinase and plasminogen on human sarcoma cells: a proteolytic system with surface-bound reactants. J Cell Biol. 1989;108:1987-1995

30. Deng G, Curriden SA, Wang S, Rosenberg S, Loskutoff DJ. Is plasminogen activator inhibitor-l the molecular switch that governs urokinase receptor-mediated cell adhesion and release? J Cell Biol. 1996;134:1563-1571

31. Hansson A, Li J, Eriksson PO, Ny T, Berggren D, Hellström S. Tympanic membrane healing in vitro. A study in plasminogen deficient mice. In: 5th Extraordinary International Symposium on Recent Advances in Otitis Media, OM2005; April 24-27, 2005; Amsterdam, Netherlands; 2005:08.02

32. Eriksson PO, Li J, Ny T, Hellström S. Spontaneous development of chronic middle ear disease due to plasminogen deficiency. Presented at: the 5th Extraordinary International Symposium on Recent Advances in Otitis Media, OM2005; April 24-27, 2005; Amsterdam, Netherlands; 2005:16.4

33. Romer J, Lund LR, Eriksen J, et al. Differential expression of urokinase-type plasminogen activator and its type- 1 inhibitor during healing of mouse skin wounds. J Invest Dermatol. 1991; 97:803-811

34. Romer J, Lund LR, Eriksen J, Pyke C, Kristensen P, Dano K. The receptor for urokinase-type plasminogen activator is expressed by keratinocytes at the leading edge during reepithelialization of mouse skin wounds. J Invest Dermatol. 1994; 102:519-522

35. Romer J, Bugge TH, Pyke C, et al. Impaired wound healing in mice with a disrupted plasminogen gene. Nat Med. 1996;2: 287-292

36. Chen A, Li HS, Hebda PA, Zeevi A, Swarts JD. Gene expression profiles of early pneumococcal otitis media in the rat. Int $J \mathrm{Pe}$ diatr Otorhinolaryngol. 2005;69:1383-1393

37. Bluestone CD, Stephenson JS, Martin LM. Ten-year review of otitis media pathogens. Pediatr Infect Dis J. 1992;11(8 suppl): S7-S1 1

38. Del Beccaro MA, Mendelman PM, Inglis AF, et al. Bacteriology of acute otitis media: a new perspective. $J$ Pediatr. 1992;120: $81-84$

39. Kilpi T, Herva E, Kaijalainen T, Syrjanen R, Takala AK. Bacteriology of acute otitis media in a cohort of Finnish children followed for the first two years of life. Pediatr Infect Dis J. 2001;20:654-662 